\title{
A descriptive study: maternal and fetal outcome of grand multipara
}

\author{
Sunder Pal Singh*, Jyoti Chawan, Divya Mangla
}

Department of Obstetrics \& Gynecology, S.H.K.M. Government Medical College, Nalhar, Mewat, Haryana, India

Received: 26 December 2014

Accepted: 11 January 2015

*Correspondence:

Dr. Sunder Pal Singh,

E-mail: sunderdahiya@yahoo.co.in

Copyright: (c) the author(s), publisher and licensee Medip Academy. This is an open-access article distributed under the terms of the Creative Commons Attribution Non-Commercial License, which permits unrestricted non-commercial use, distribution, and reproduction in any medium, provided the original work is properly cited.

\begin{abstract}
Background: Pregnancies in grand multipara have been considered risky for many decades as there are higher chances of complications during pregnancy, labour and puerperium in these women. This study aims to find out various maternal and fetal complications associated with grand multiparty during pregnancy and labour.

Methods: A descriptive observational study was conducted in the department of obstetrics and gynecology of S.K.H.M Medical College Nalhar, Mewat, from Jan, 2014 till Oct, 2014. It included 100 cases of grand multipara women. All the women who delivered at S.K.H.M and had five or more previous viable pregnancies were included in the study.

Results: In the total 100 cases that were included in the study, the common medical illness found in grand multipara were anemia (92\%), hypertension (13\%), preeclampsia $(9 \%)$ eclampsia $(4 \%)$ and diabetics mellitus $(2 \%)$. Other complications observed were mal-presentations $(18 \%)$, intra-uterine deaths $(18 \%)$, preterm labor $(15 \%)$, placental abruption (8\%), shoulder dystocia (6\%), placenta previa (5\%), obstructed labour $(4 \%)$, and ruptured uterus $(2 \%)$. Caesarian section was required in $28 \%$ of the cases. Third stage complications were also high in grand multi para e.g. PPH $(14 \%)$, retained placenta $(5 \%)$, uterine inversion $(3 \%)$ and maternal mortality $(4 \%)$. In perinatal outcomes the observations were lbw babies (15\%), macrosomies (10\%), and APGAR score (8-10) in $70 \%$ of the babies.

Conclusions: Grand multiparity is still a major obstetric hazard which needs strict supervision and good antenatal care and active intervention at appropriate time. Extreme parity should be treated with extra care especially in populations with high rates of unbooked deliveries.
\end{abstract}

Keywords: Grand multiparity, Pregnancy outcome, Rural setting

\section{INTRODUCTION}

The pregnancy complications are directly related to parity and continue to be a challenge to the obstetricians. Pregnancies in grand multipara have been considered risky for many decades as various complications have been observed during pregnancy, labour and puerperium with increased parity. International federation of gynecology and obstetrics, refers to grand multiparity as delivery of fifth to ninth infant, whereas women who deliver tenth or more babies are considered to be great grand multiparas. ${ }^{1}$ In terms of minimal risk the safest pregnancies are second, third and fourth. The hazards are greater in the fifth pregnancy and onward. ${ }^{2}$
Some complications that are classically associated with grand multiparty include; fetal malpresentations, dysfunctional labour, abruption placentae, placenta previa, anemia, third stage complications like PPH, retained placenta and uterine inversion. Ruptured uterus, macrosomic babies are also more commonly observed in grand multipara. In developed countries grand multiparty is becoming rare but in developing countries it is higher and considered a public health problem. Anemia both iron and folic acid deficiency is the commonest problem associated with grand multiparty. Hypertensive disorders are found with increased frequency in grand multiparity. ${ }^{3,4}$ Advanced maternal age, obesity may play important role in its development. There is 5.6 fold 
increased risk of placenta previa in these women. Premature separation of normally situated placenta also occurs more frequently in them. ${ }^{5}$ There are higher frequencies of malpresentations in grand multipara. These malpresentations directly affect the outcome of labour by causing higher incidence of obstructed labour, prolonged labour and operative delivery which increases maternal mortality and morbidity as well as perinatal mortality. ${ }^{6-8}$ Cesarean rates are also high in grand multiparty due to malpresentations, malposition, likelihood of CPD, twin pregnancy, placenta previa and placental abruption., ${ }^{9,10}$

The incidence of both spontaneous and induced abortions due to unwanted pregnancy is very high in GMP women. It is one of the major causes of maternal deaths. Rupture of uterus is the gravest complication of high parity. ${ }^{20}$ Third stage complications like $\mathrm{PPH}$, retained placenta also occur more frequently in these women due to atony of uterus, lack of retraction and injuries to genital tract. There is increased incidence of twin pregnancy in GMP due to high parity and maternal age. ${ }^{11}$ Perinatal mortality is also high due to PTL, PROM, placental abruption, congenital malformations etc. The risk of fetal chromosomal abnormality particularly trisomy 21 rises sharply with maternal age. ${ }^{12,13}$

\section{METHODS}

This study was conducted at the department of obstetrics and gynecology, S.K.H.M GMC Mewat, Haryana. The study is a descriptive type of study. The present study was conducted during Jan, 2014 to Oct, 2014. All antenatal women who had five or more previous viable pregnancies were included in the study. All the women with less than five viable pregnancies were excluded from the study. Multiple pregnancies were counted as a single pregnancy and abortion, ectopic pregnancy and $\mathrm{H}$. Mole were not included in the parity. About hundred patients according to the inclusion criteria were included in the study. Informed consent was taken from the all study participants. Most of the patients were unbooked. A detailed history of the patient was taken with through physical examination and base line investigations like hemoglobin, blood group, blood sugar, urine examination and USG were carried out. Study protocol was approved by institutional ethical committee.

\section{RESULTS}

Out of one hundred consecutive cases of grandmultiparity included in the study, $95 \%$ of the cases were unbooked, most of those already had trial of labour at home or in other primary or secondary health care centers and were referred here with complications. Most of these women belonged to $35-40$ years of the age group (56\%). Frequency of GMP was more in low socioeconomic class $(85 \%)$ (Table 1).
Table 1: Socio-demographic distribution of study participant.

\begin{tabular}{|lll|}
\hline \multicolumn{3}{|c|}{$\begin{array}{c}\text { Frequency } \\
(\mathrm{N}=100)\end{array}$} \\
\hline Age & Percentage \\
\hline $30-35$ & 29 & $29 \%$ \\
\hline $35-40$ & 56 & $56 \%$ \\
\hline$>40$ & 15 & $15 \%$ \\
\hline Socioeconomic class \\
\hline I & 0 & 0 \\
\hline II & 0 & 0 \\
\hline III & 2 & $2 \%$ \\
\hline IV & 13 & $13 \%$ \\
\hline V & 85 & $85 \%$ \\
\hline Registered ANC \\
\hline Yes & 5 & $5 \%$ \\
\hline No & 95 & $95 \%$ \\
\hline
\end{tabular}

The most common complication encountered in grand multipara was anemia (92\%), with majority having $\mathrm{Hb}$ between $7-8 \%$ and about $35 \%$ had a $\mathrm{Hb}$ level $<5 \mathrm{gm} \%$. Hypertension was observed in $13 \%$ cases. Preeclampsia was observed in $9 \%$ cases and eclampsia occurred in $4 \%$ cases. Diabetic mellitus was found in $2 \%$ of cases.

Ante partum hemorrhage was observed in $13 \%$ of the cases which included placenta previa $(5 \%)$ and placental abruption (8\%). Multiple pregnancies were observed in $8 \%$ of the total cases.

$18 \%$ of the women were reported with malpresentation and Breech was the most common malpresentation reported in our study. 15 cases were reported for the Pre term delivery and all of these women came to the hospital in the advance stage of the labour. 8 of these women have pre mature rupture of membrane. 6 cases of shoulder dystocia were reported during the labour and obstructed labour was noticed in $4 \%$ of the patients.

Table 2: Pregnancy outcome in grand multipara $(\mathrm{N}=100)$.

\begin{tabular}{|lll|}
$\begin{array}{l}\text { Pregnancy } \\
\text { complications }\end{array}$ & $\begin{array}{l}\text { Frequency } \\
(\mathrm{N}=100)\end{array}$ & Percentage \\
\hline Anemia & 92 & $92 \%$ \\
\hline Hypertension & 13 & $13 \%$ \\
\hline Eclampsia & 4 & $4 \%$ \\
\hline Diabetes & 2 & $2 \%$ \\
\hline APH & 13 & $13 \%$ \\
\hline Multiple pregnancy & 8 & $8 \%$ \\
\hline Malpresentations & 18 & $18 \%$ \\
\hline Preterm delivery & 15 & $15 \%$ \\
\hline Obstructed labour & 4 & $4 \%$ \\
\hline Shoulder dystocia & 6 & $6 \%$ \\
\hline
\end{tabular}

$64 \%$ of the women delivered normally while $8 \%$ women delivered with the help of vacuum and forceps. 
Caesarian section was required in $28 \%$ of the cases. During the caesarean 3 patients landed in PPH and underwent caesarean hysterectomy.

Labour induction rates were high (30\%) due to intrauterine fetal death, fetal anomalies, post maturity, PROM, severe preeclampsia-eclampsia. Induction with Trans-cervical Foleys catheter followed by amniotomy and oxytocin was the commonest method of induction.

Table 3: Mode of delivery in grand multipara.

\begin{tabular}{|lll|}
\hline Obstetric outcome & $\begin{array}{l}\text { Frequency } \\
(\mathrm{N}=100)\end{array}$ & Percentage \\
\hline Normal vaginal & 64 & $64 \%$ \\
\hline Vaginal assisted vacuum & 7 & $7 \%$ \\
\hline Forceps & 1 & $1 \%$ \\
\hline Caesarean Section & 28 & $28 \%$ \\
\hline
\end{tabular}

About $70 \%$ had less than 12 hours of labour while a few had prolonged labour resulting in higher maternal mortality and poor perinatal outcome. Perineal tears and instrumental deliveries were less commonly observed in GMP. Only 1 case of third degree of perineal tear was observed in instrumental delivery. Post-partum hemorrhage which was the most common complication in our study occurred in $14 \%$ of patients. Retained placenta observed in 5\% cases. Almost all cases with retained placenta were brought to hospital after home delivery and were due to uterine atony. All of these patients were presented in hemorrhagic shock due to $\mathrm{PPH}$, retained placenta, rupture uterus. Three cases of uterine inversion were reported all of those had home delivery.

There were 4 maternal deaths, one was due to massive atonic PPH leading to irreversible hemorrhagic shock where the patient was referred with severe preeclampsia in second stage of labour. Second death was due to DIC because of APH. Two patients died due to CHF because of severe anemia, one of which died in immediate postpartum period after caesarean section and the other died in her antenatal period at 32 weeks of gestation.

Table 4: Obstetrics complications in grand multipara.

\begin{tabular}{|lll|}
\hline Obstetric outcome & $\begin{array}{l}\text { Frequency } \\
(\mathrm{N}=100)\end{array}$ & Percentage \\
\hline PPH & 14 & $14 \%$ \\
\hline Retained placenta & 5 & $5 \%$ \\
\hline Uterine Inversion & 3 & $3 \%$ \\
\hline Third degree perianal tear & 1 & $1 \%$ \\
\hline Uterine rupture & 2 & $2 \%$ \\
\hline Maternal mortality & 4 & $4 \%$ \\
\hline
\end{tabular}

A total of $82 \%$ babies were born alive. $70 \%$ of these had an APGAR score of 8to10. 12\% of these had an APGAR score less than 5. Almost all of them died in the neonatal period. $18 \%$ were born dead.
$15 \%$ of the babies were reported to have Low Birth Weight. $10 \%$ of the babies were macrosomic babies out of which 1 macrosomic baby was delivered by diabetic women. $8 \%$ babies were found to have congenital malformation. The most common congenital anomaly was anencephaly. Birth asphyxia, neonatal sepsis were common causes of neonatal morbidity.

Table 5: Perinatal outcome in grand multipara.

\begin{tabular}{|lll|}
\hline Birth outcome & Frequency & Percentage \\
\hline Live birth & 82 & $82 \%$ \\
\hline Intrauterine deaths & 18 & $18 \%$ \\
\hline LBW babies & 15 & $15 \%$ \\
\hline Macrosomic babies & 10 & $10 \%$ \\
\hline Congenital malformations & 8 & $8 \%$ \\
\hline
\end{tabular}

\section{DISCUSSION}

The problems of extreme parity seems to be nonexistent in developed countries however in developing countries in certain areas multiple child births still exists in significant numbers, perhaps related to cultural or religious beliefs.

This study is of interest because of this region's social characteristics where a high prevalence of grand multiparity coexists with substandard level of care during delivery and antenatal time.

Grand multiparity and maternal mortality are closely related because of repeated pregnancies and child birth. In our study more than $85 \%$ patients were admitted in emergency and no antenatal care was given in these cases.

Low socioeconomic class contributed to grand multiparity in our study and other few study also observed the same.

About $85 \%$ patients were $30-40$ years of age. Age related risks of grand multiparity like obesity, chronic hypertension, placenta previa, placental abruption, ${ }^{18}$ GDM, macrosomic infant cause a great threat to both mother and fetus. ${ }^{6}$

Stein et al. also observed that the incidence of these diseases increased with advanced maternal age. ${ }^{14}$

McGillivrari also found that chronic hypertension and twinning increase with maternal age. ${ }^{4}$

Increasing birth order also increases the frequency of hypertension, diabetes, placental complications, chromosomal abnormalities and operative intervention. ${ }^{15}$ In our study also the frequency of these disorders was high.

The cases of anemia in our study were $92 \%$. One study has recorded $45 \%$ incidence. 
The frequency of pre eclampsia in our study was $9 \%$. This is similar to a study by Al Sibai et al. (1987) $)^{4,16}$ in which the incidence was $6.1 \%$.

Our study observed DM in $2 \%$ of the cases and our study also revealed increased cases of fetal macrosomia, IUD, anencephaly and hydramnios in diabetic GMPs. One study has recorded $9.9 \%$ frequency of glucose intolerance in GMP women. This is in contrast to a study by Al Sibai et al. in which DM caused the least pre-delivery complications. ${ }^{16}$

Frequency of malpresentations in GMP in our study was $18 \%$. Babinsky et al. reported higher frequencies of malpresentations in GMP. ${ }^{8,17}$ This is also comparable with other studies.

Our frequency of primary PPH was $14 \%$. Nabeel et al. reported incidence of $13.4 \%$ (2005).

Razina et al. (2009) have reported an incidence of $9 \% .{ }^{19}$

In our study $2 \%$ patients came with retained placenta which is comparable with other studies.

Preterm delivery in GMP in our study was $15 \%$. Al Sibai et al. and Babinski et al. also showed a higher cases of preterm labour in grand multipara similar to our study. ${ }^{16,17}$

Frequency of IUD in our study was $18 \%$. The reported cases for IUD in grand multipara is $5.2 \%$.

Our study showed that pregnancy and delivery are at greater risk in grand multipara. Maternal morbidity and mortality are also increased. This is similar to the results of previous studies. ${ }^{6-8}$

\section{CONCLUSION}

Grand multiparity is still a major obstetric hazard in developing countries, where illiteracy, socio economic background and religion are the key factors to contribute towards grand multiparity. As it is concluded in this study, GPM is one of the most common cause of maternal and fetal mortality and morbidity. At first GPM should be strictly avoided by spreading the health education and by improving the socio economic status of the families. If at all GPM occurs then it needs strict supervision and good antenatal care and active intervention at appropriate time. Extreme parity should be treated with extra care especially in populations with high rates of unbooked deliveries.

Funding: No funding sources Conflict of interest: None declared

Ethical approval: The study was approved by the institutional ethics committee

\section{REFERENCES}

1. Hoque M, Hoque E, Kader SB. Pregnancy complications of grand multiparity at a rural setting of South Africa. Iran J Reprod Med. 2008;6(1):2531 .

2. Aslam M. Grand multiparity. J Med Sci. 1994;10(4):317-21.

3. Abu Heija AT, Chalabi HE. Great grand multiparity; is it a risk? Int $\mathrm{J}$ Gynecol and Obstet. 1997;59(3):213-6.

4. MacGillivray I. Preeclampsia. In: MacGillivray I, eds. The Hypertensive Disease of Pregnancy. 1st ed. London: WB Saunders; 1983.

5. Zaidi S. The role of the obstetrician in reducing perinatal mortality. In: Zaidi S, eds. Maternal and Perinatal Health. 2nd ed. Karachi: TWEL Publishers; 1992: 115.

6. Shamshad B. Age and parity related problems affecting outcome of labour in grand multiparas. Pak J Med Res. 2003;42(4):179-84.

7. Zaheera S, Robina F, Fehmida N. Maternal outcome in grand multiparas. Ann King Edward Med Coll. 2002;8(3):207-10.

8. Shehla N, Nasreen RF, Shagufta M. Malpresentation incidence and causes. J Postgrad Med Inst. 2001;15(1):33-8.

9. Ashraf T. Maternal mortality. A four year review. J Col Phys Sur Pak (JCPSP). 1995;6(3):159-61.

10. Gardner MJ, Altman DG. Cesarean rates. Gardner MJ, Altman DG, eds. Statistics with Confidence. 4th ed. London: BMJ Books; 2000.

11. MacGillivray I, Samphier M, Little J. Factors affecting twinning. In: MacGilivray I, Campbell DM, Thompson B, eds. Twinning and Twins. 6th ed. US: John Wiley \& Sons: 1998; 67-97.

12. Holloway S, Brock DJH. Changes in maternal age distribution and their possible impact on the demand for prenatal diagnostic services. $\mathrm{Br}$ Med J. 1988;296;978-81.

13. Ferguson-Smith MA, Yates JRW. Maternal age specific rates for chromosome aberrations and factors influencing them: report of a collaborative European study on 52956 amniocenteses. Prenat Diagn. 1984;4:35-44.

14. Stein AZ. A woman's age: childbearing and child rearing. Am J Epidemiol. 1985;121:327-42.

15. Malik S, Naz F. Grandmultiparity: a continuing obstetric risk. J Surg Pak. 2001;6(2):29-31.

16. Al-Sibai MH, Rehman MS, Rahman J. Obstetric problems in the grand multipara: a clinical study of 1330 cases. J Obstet Gynecol. 1987;8(2):135-8.

17. Babinski A, Kerenyi T, Torok O, Grazi V, Lapinski RH, Bertwitz RL. Perinatal outcome in grand and great grand multipara effects of parity on obstetric factos. Am J Obstet Gynecol. 1999;181:669-74.

18. Cande V, Ananth AJ, Savitz DA, Bowes WA, Luther ER. Effects of maternal age and parity on the risk of uteroplacental bleeding disorders in pregnancy. Am J Obstet Gynecol. 1996;88(4):51. 
19. Rozina Shahid, Mamoona Mushtaq. Complications of grand multiparity. Pak J Armed Forces. 2009 Sep;(4):1-5.

20. Ummi H, Zaibunnisa K, Manzoor A. A review of 66 cases of ruptured uterus in a district general hospital. J Postgrad Med Inst. 2002;16(1):49-54.
DOI: $10.5455 / 2320-1770$. ijrcog20150239

Cite this article as: Singh SP, Chawan J, Mangla D. A descriptive study: maternal and fetal outcome of grand multipara. Int J Reprod Contracept Obstet Gynecol 2015;4:219-23. 